\title{
$\bullet$ Foetal Anomalies: Correlative Study of Sonography and Autopsy
}

\section{IJCRR}

Section: Healthcare

ISI Impact Factor

(2019-20): 1.628

IC Value (2019): 90.81

$\operatorname{SJIF}(2020)=7.893$

(c) (i) (8)

Copyright@IJCRR

\section{Aiswarya Lekshmi RV ${ }^{1}$, G Rajư ${ }^{2,3}$, K Chandrakumari ${ }^{4}$}

'Assistant Surgeon, W\&C Hospital, Thycaud, Thiruvananthapuram, Kerala, India; ${ }^{2}$ Assistant Professor, Department of Anatomy, Sree Gokulam Medical College \& Research Foundation, Thiruvananthapuram, Kerala, India; ${ }^{3 R e s e a r c h ~ S c h o l a r, ~ V i n a y a k a ~ M i s s i o n ' s ~ R e s e a r c h ~ F o u n d a t i o n ~}$ (Deemed to be University), Salem-636308, Tamilnadu, India; 4Professor and Head, Department of Anatomy, Sree Gokulam Medical College \& Research Foundation, Thiruvananthapuram, Kerala, India.

\section{ABSTRACT}

Background: Sonography is performed without risk to mother or foetus for a scientific anatomical survey of the external features and all organs related to each system.

Objectives: In this study by comparing Ultrasound and Autopsy of intrauterine congenitally anomalous foetuses contrasting findings were detected.

Methods: The results of Limb anomalies, Palmar crease defect, Cleft palate and Cleft lip, Club foot, Diaphragmatic hernia, Gastrointestinal anomalies like Omphalocele, Imperforate Anal defects are considered.

Results: Four categorizations of anomalies with the comparison of Ultrasound and Autopsy findings are done.

Conclusion: Categorization plan shows that each Ultrasound and Autopsy findings are influenced by Socio-economic status and Dietary habits. Early diagnosis of malformations and awareness to parents can be helpful for Medical termination of pregnancy and prevention in subsequent pregnancies.

Key Words: Autopsy, Categorization, Sonography

\section{INTRODUCTION}

This study aims to analyse the potential use of Prenatal scan done throughout intrauterine life from 6-20 weeks for the assessment and diagnosis of defective embryological anomalies. Sonography is performed without risk to mother or foetus for a scientific anatomical survey of the external features and all organs related to each system. Two broad subsets of foetal anomalies are major and minor. Minor anomalies about $14 \%$ which won't seriously interfere with viability or physical well being which can or cannot be detected during Prenatal sonography. In this study pattern of different embryological anomalies and sex ratios of foetuses were conducted. ${ }^{1-3}$

\section{MATERIALS AND METHODS}

Source: Fifty Antenatal Ultrasound scan reports of defective embryological anomalies and their foetal specimens obtained after medical termination of pregnancy or delivery.
Study Design: Descriptive Study Case series.

Data Analysis: Student t-test using SPSS Software version 17 and Microsoft Excel.

\section{MATERIALS}

This study (SGMC: IEC No.10/95/01/2014/) was conducted from 2014 to July 2016. Ultrasound scanning reports obtained from Ittyavirah Scan Centre, Thiruvananthapuram. Specimens of those foetuses were obtained from various hospitals were delivery or medical termination was conducted including Placenta. The autopsy was conducted at Sree Gokulam Medical College \& Research Foundation, Thiruvananthapuram.

\section{Inclusion criteria}

Embryologically defective foetuses detected by Autopsy, agreeing with their Ultrasound Scan reports.

\section{Corresponding Author:}

Aiswarya Lekshmi R V, Assistant Surgeon, W\&C Hospital, Thycaud, Thiruvananthapuram, Kerala, India; Email: aisuleks@gmail.com

ISSN: $2231-2196$ (Print)

ISSN: 0975-5241 (Online)

Received: 30.08 .2020

Revised: 20.11 .2020

Accepted: 15.12 .2020

Published: 16.01 .2021 


\section{Exclusion criteria $^{4-6}$}

Embryologically defective foetuses whose Ultrasound Scan reports are not available. Detailed recording of the history of the patients was obtained from parents in the form of a Proforma including, maternal age, Duration of gestation, history of consanguineous marriage, socio-economic status, history of the maternal consumption of medicine taken by the mother during pregnancy, history of dietary habits, exposure to radiation, chemicals, history of abortions or stillbirths, previous history of defective embryological anomalies and similar history in the family.

The cases were followed up till delivery or Medical termination of pregnancy at various hospitals in Thiruvananthapuram. The fetuses after expulsion/delivery were collected. The external appearances of the babies were examined $\&$ noted down and compared with the Ultrasound reports. Collected foetuses and Placenta were obtained ranging from sixteen to twenty weeks of gestation were preserved in $10 \%$ formalin which is the fixative used. Consent for Autopsy was obtained from parents after explaining the necessity. The Autopsies were conducted in the Department of Anatomy, Sree Gokulam Medical College after comparing with the Ultrasound report. Each foetus was exploded using the surgical knife, scissors and forceps. Internal findings correlated with the Ultrasound and other extra findings looked for. Updating of findings was done by periodical photography and placenta is also studied. ${ }^{7-9}$

\section{RESULTS}

Correlating the findings of Prenatal, Ultrasound and Foetal Autopsy of the specimens of varied Congenital anomalies classification was done system-wise under the following four categories. ${ }^{10-12}$

Category A - Both findings (Ultrasound and Autopsy) were agreed.

Category B - Additional data of other anomalies detected.

Category C - Foetal autopsy revealed only certain Ultrasound findings.

Category D - Ultrasound and Autopsy findings were mismatching.

\section{LIMB ANOMALIES}

\section{Talipes Equino Varus}

Sixteen foetuses showed Talipes Equino Varus. Out of that four specimens had shortening of Upper and Lower segments of both limbs due to Skeletal dysplasias as given in Figure 4 and Table 1.
A combination of talus and pes together with an elevated heel resembling that of a horse (L. Equinus, horse); which is also turned inwards (Varus). Inverted foot, Plantarflexed ankle, Adducted forefoot as shown in Figure 1 (turned toward the midline abnormally). Incidence is approximately one per thousand live births with males affected twice than females. ${ }^{1,2}$
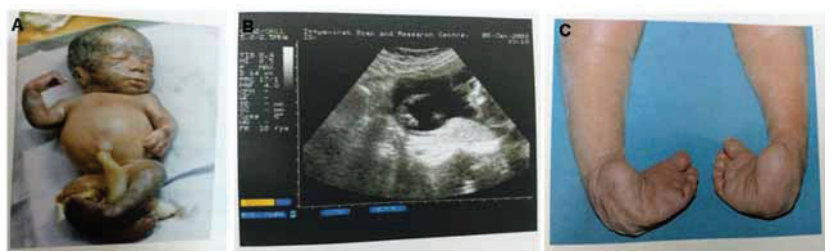

Figure 1: A. Foetus with Club foot, B. Ultrasound Picture shows Encephalocele \& Club foot and C. Foetus with bilateral Talipes Equino Varus.

\section{Table 1: Limb Anomalies}

\begin{tabular}{lcc} 
Limb Anomalies & Frequency & Percentage \\
$\begin{array}{l}\text { Upper and Lower segments of } \\
\text { both limbs shorter }\end{array}$ & 4 & 8.0 \\
Presence of TEV & 16 & 32.0 \\
\hline
\end{tabular}

\section{Omphalocele}

Three fetuses were there with Omphalocele as shown in Figure 2. Other findings in one foetus are, short neck with oedema around, head twisted towards right, left lower limb absent, spine with scoliosis, right foot with 1,2 and 3 toes fused, ambiguous genitalia, omphalocele contain intestine and liver, umbilical cord contains one umbilical artery and kidney was Horseshoe shaped shown in Figure 3.
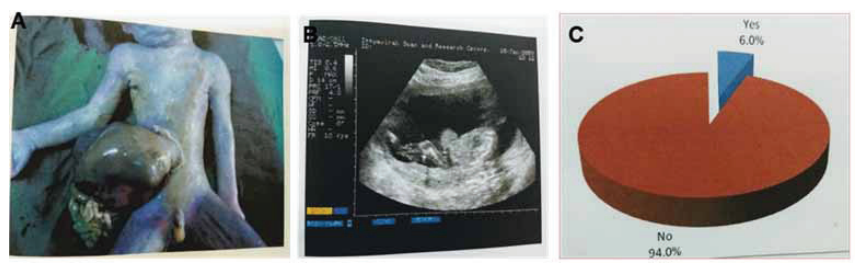

Figure 2: A. Foetus with Omphalocele, B. Ultrasound picture of Omphalocele and $C$. Incidence of omphalocele.

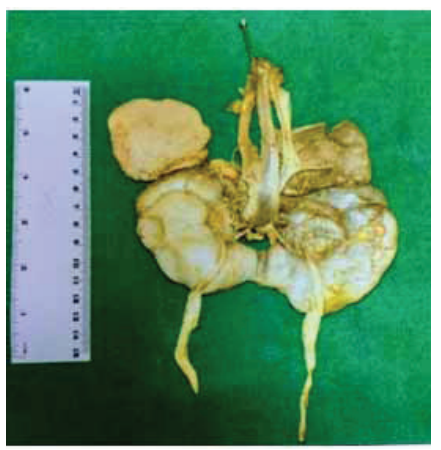

Figure 3: Autopsy Specimen of Horse Shoe Kidney. 


\section{List of abnormalities in Second specimen}
i. Short neck
ii. Dysmorphic facies
iii. Fusion of digits of Hand and Feet.
iv. Left Foot Talipes Equino Varus.
v. Single Palmar Crease.
vi. Lungs were two lobbed.

Third Specimen presented only with Omphalocele.

\section{Cleft Palate}

Cleft Palate constitutes $4 \%$ of the total anomalies as shown in Figure 4. One was a male baby with dysmorphic facies, low set ears with flattened ear lobes, upper lip bilateral cleft lip with cleft palate, nose poorly formed, polydactyly with six digits in the left hand and right foot, the phallus is short with Hypospadias.

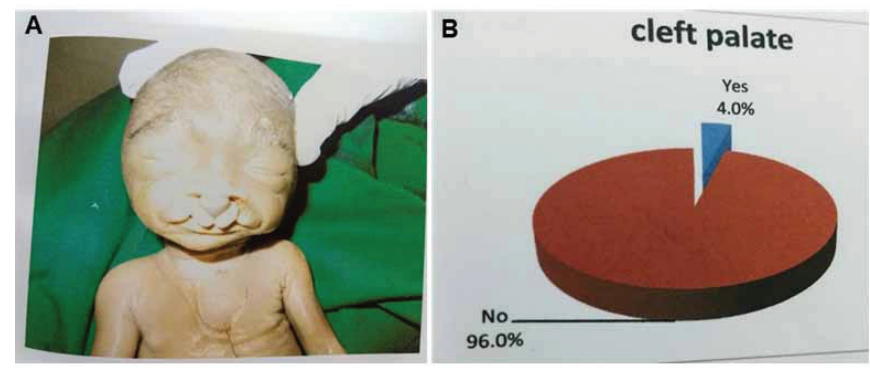

Figure 4: A. Foetus with Cleft Lip/Cleft Palate and B. Occurance (percentage) of Cleft Palate.

\section{Diaphragmatic Hernia}

There were three cases of Diaphragmatic Hernia which shows the frequency is more on the left side as shown in Table 2 and Figure 5.

\section{Table 2: Diaphragmatic Hernia}

\begin{tabular}{lcc} 
Diaphragmatic Hernia & Frequency & Percentage \\
Left & 3 & 6.0 \\
Right & 0 & 0.0 \\
\hline
\end{tabular}

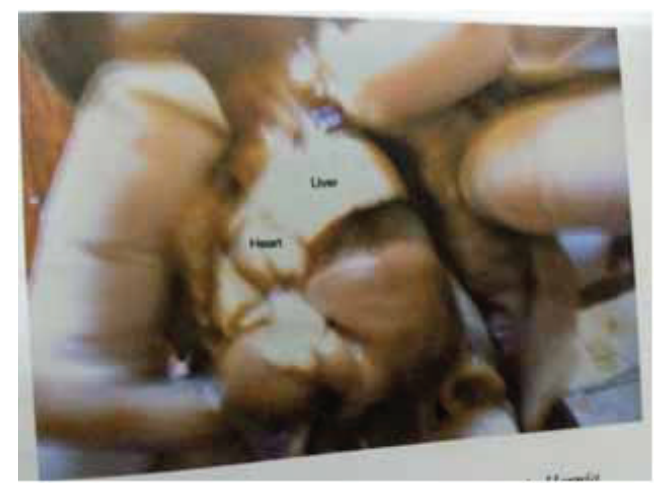

Figure 5: Autopsy shows Diaphragmatic Hernia.

\section{Imperforate Anus}

Detected in three foetuses shown in Table 3. Two of them were with Mermaid syndrome.

\section{Table 3: Imperforate Anus}

\begin{tabular}{lcc} 
Imperforate Anus & Frequency & Percentage \\
Yes & 3 & 6.0 \\
No & 47 & 94.0 \\
Total & 50 & 100.0 \\
\hline
\end{tabular}

\section{Single Palmar Crease}

It was hydrops baby with multiple Congenital anomalies, dysmorphic facies, short neck, the fusion of digits of hand and feet, left foot Talipes Equino Varus, Single Palmar crease, Omphalocele and both lungs were two lobbed shown in Figure 6 and Table 4.

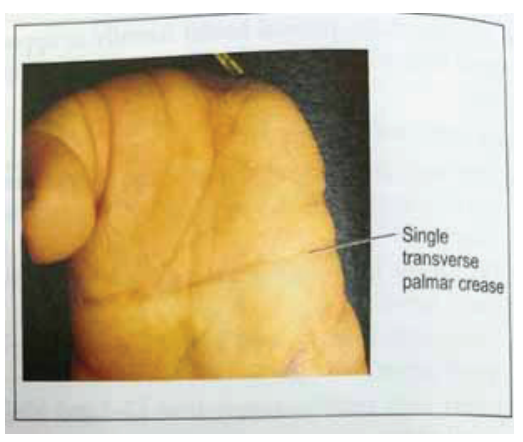

Figure 6: Single transverse palmar crease.

(Photo Courtesy: Dr. Kumaravel S, Dr. Yogesh Sontakke)

\section{Table 4 : Single Palmar crease}

\begin{tabular}{lcc} 
Single Palmar crease & Frequency & Percentage \\
Yes & 1 & 2.0 \\
No & 49 & 98.0 \\
Total & 50 & 100.0 \\
\hline
\end{tabular}

\section{DISCUSSION}

In this study Ultrasound and Foetal Autopsy findings of Foetuses up to 20 weeks of gestation were compared and contrasted. Antonsson et $\mathrm{al}^{13}$ examined Ultrasound and $\mathrm{Au}-$ topsy on an equivalent methodological basis and concluded that autopsy could have significant limitation in CNS malformations. During this study, we could ready to notice a high degree of correlation between Ultrasound and Autopsy in twenty-two cases. $44 \%$ of Foetal anomalies revealed in Ultrasound have demonstrated in Autopsy also. These anomalies are grouped under Category A which incorporates neural tube defects, Cystic hygroma, Hydrops foetal is and Omphalocele. ${ }^{14-16}$ 
Akgun et $\mathrm{al}^{17}$ in 2007 concluded that analysis of Foetal autopsy following termination of pregnancy enables the diagnosis of anomalies which isn't detected by Ultrasound. In Category B, limb anomalies, Skeletal defects and Genitourinary anomalies are included mostly. Skeletal dysplasia is often revealed through Ultrasound, but confirmation is required from the autopsy. Renal Cystic diseases could even be difficult to define on an Ultrasound scan as Oligohydramnios is usually associated. Other anomalies like Cardiovascular, Cleft lip/Cleft palate and Urinary tract defects are detected in autopsy (Category B) 38\%. ${ }^{18-21}$

Category C included mainly complex, CNS because it gets macerated due to improper preservation of the foetus after death and also due to the delay in the autopsy. Moreover, it should be borne in mind that certain conditions of expulsion hinder examination as they involve an excessively long period of foetal retention resulting in maceration in Utero and tissue lysis, of brain tissue especially and Cardiovascular anomalies like Valve insufficiencies due to the small size of the heart, Pericardial and Pleural effusions. Seven cases were included in Category $\mathrm{C}$ which constitutes $14 \%$ of the entire anomalies. ${ }^{20}$

In Category D there was total disagreement between U1trasound and Autopsy. Two cases come under Category D which constitute $4 \%$ of the entire anomalies. Finally, this categorization shows that both Ultrasound and Autopsy may have some important limitations in diagnosing Foetal abnormalities and both are complementary. ${ }^{21,22}$ The mothers who had undergone Ultrasound scanning and were found to be having Congenitally abnormal foetuses were grouped consistent with the Socio-economic status into High, Middle and Low-income groups.

\section{CONCLUSION}

Reasons for Common defective embryological anomalies are genetic factors (Chromosome and Single gene mutation), environmental factors (Infectious agents, Chemical compounds, Radiations), use of medication by mother, maternal metabolic diseases, multiple pregnancies maternal stress and prematurity of the Infant. By this study the potential and limitations of Ultrasound and Autopsy and categorization into four categories as possible. Even though Ultrasound fairly detects the malformations, Foetal autopsy is vital for obtaining extra information. Ultrasound findings rely upon the accuracy of the machine and the experience of the person. The Autopsy also depends on the ability and experience of a Specialist Paediatric Pathologist. The placental examination is also can give supportive findings like Macroscopic study of the Placenta, Position of Umbilical cord, Foetal and Maternal surfaces of the Placenta and Evidence of Placental infections. Earlier detection of Foetal anomalies by Ultrasound leads to early termination of Pregnancy without Autopsy. This results in missing important pieces of information from Paediatric Pathologist which can cause risk of repetition in the subsequent pregnancies. Defective embryologically malformed infants are prone to morbidity and mortality. Treatment and Rehabilitation of these infants are tough. Recovery is usually not possible. So early diagnosis, interpretation and awareness to parents are very crucial.

\section{ACKNOWLEDGEMENTS}

We acknowledge the contribution of Dr. AK Ittyavirah, Radiologist and Ultrasonologist, Ittyavirah Scan and Research Centre, Thiruvananthapuram and therefore the faculties of the department of Anatomy. We are thankful to Dr. A E Chudley, Moore K L, Dalley FA, Dr. Kumaravel S, Dr. Yogesh Sontakke and MR Anne for providing quality pictures.

Conflicts of interest: All authors have none to declare.

Financial support and sponsorship: No funding to declare.

\section{REFERENCES}

1. Antonsson P, Sundberg A, Kublickas M. Correlation between Ultrasound \& Autopsy findings after $2^{\text {nd }}$ Trimester terminations of Pregnancy. J Perinat Med 2008;36(1):59-69.

2. Hulya A, Mustafa B, Mahmut TO. Correlation between Prenatal Ultrasound \& Foetal Autopsy findings in Foetal anomalies terminated in the second trimester. Prenat Diagn 2007;27:45762.

3. Kaasen A, Tuveng A, Heiberg AE. Correlation between Prenatal Ultrasound and autopsy findings: a study of second trimester abortions. Ultrasound Obstet Gynecol 2006;28:925-933.

4. Taboo ZA. Prevalence and Risk Factors for Congenital Anomalies in Mosul City. Iraqi Postgraduate Med J 2012;11(4):458470.

5. Pradhan R, Mondal S, Adhya S, Chaudhuri GR. Perinatal Autopsy: A study from India. J Indian Acad Forensic Med 2013;35(1):971-973.

6. Amini H, Antonsson P, Papadogiannikis N. Comparison of Ultrasound and autopsy findings in Pregnancies terminated due to foetal anomalies. Acta Obstet Gynecol Scandinavica 2006;85:1208-1216.

7. Globus MS, Hall BD, Filly RA, Poskanzer LB. Prenatal diagnosis of achondrogenesis. J Paediatrics 1977;91:464.

8. Persaud TV. Problems of Birth Defects: From Hippocrates to Thalidomide \& after. Baltimore, University Park Press 1979:12:345-349.

9. Sun CJ, Grumbach KN, DeCosta TD. Correlation of Prenatal Ultrasound Diagnosis and Pathologic Findings in Foetal Anomalies. Pediatr Dev Pathol 1999;2(2):131-142.

10. Nayab A, Irshad A, Amir HM. CongenitalAnomalies: Prevalence of Congenital anomalies in $2^{\text {nd }}$ Trimester of Pregnancy in Madina Teaching Hospital, Faisalabad on greyscale ultrasound. JUMDC 2010;1(1):1-6.

11. Devi R, Tilak P, Rajangam S. Multiple Congenital anomaliesanaetiological Evaluation. Bombay Hospital J 2007;2(5):64-69.

12. Kulkarni ML. Congenital malformation. Indian Paediatr 1989;26:5-9. 
13. Bai N S, Mathew E, Nair PM, Sabrinathan K.Perinatal mortality during a South Indian Population. J Indian Med Assoc1991;89:97-98.

14. Sharma A K.The Clinical Value of Perinatal Autopsy. Indian Paediatr 1994;31:5-7.

15. Valerie D, Luc L. Fetal and Perinatal Autopsy in Prenatally Diagnosed Foetal Abnormalities with Normal Karyotype. SOGC Tech Update 2011; 267:1047-1057.

16. Arthur C, Fleischer M D, Sandra G, Krihner MD, Grey A, Thoma MD.Prenatal detection of foetal anomalies with Ultrasonography. Paediatr Clin North Am 1985;32(6): 326-329.

17. Tanaka K, Miyajima G, Wagai T, Yasuura M. Detection of Intracranial anatomical abnormalities by ultrasound. Tokyo Med J 1950;69:52.
18. Mishra PC, Baveja R. Congenital anomalies in Newborns A Prospective study. Indian Paediatrics 1989;26:123-126.

19. Ghosh S, Bhargava SK, Bhutani R. Congenital anomalies in longitudinally studied birth cohort in an urban community. Indian J Med Res 1985;82:427.

20. Mohan H, Bhardwaj S, Bal A. Congenital Visceral Malformations Role of Perinatal Autopsy in diagnosis. Foetal Diag Ther 2004;19:131-133.

21. Aiyar RR, Agarwal JR. Observation on Newborn: A Study of 10,000 consecutive live births. Ind Paediatr 1969;6:729-742.

22. Vimercati A, Grasso S, Abruzzese M, Chincoli A, de Gennaro A, Miccolis A. Correlation between Ultrasound diagnosis and autopsy findings of foetal malformations. J Prenat Med 2012;6(2):13-17. 